\title{
Professionally responsible for counseling Pregnant Women about Abortion and Feticide
}

\author{
${ }^{1}$ Frank A Chervenak, ${ }^{2}$ Laurence B McCullough
}

\begin{abstract}
We provide comprehensive, practical guidance for physicians on when to offer, recommend, perform, and refer patients for induced abortion and feticide based on the professional responsibility model of obstetric ethics. We begin by defining clinical terminology and elucidating autonomy-based and beneficencebased obligations as well as professional conscience and individual conscience. The obstetrician's role in counseling the pregnant woman about abortion and feticide should be based primarily on professional conscience, which is shaped by autonomy-based and beneficence-based obligations of the obstetrician to the pregnant and fetal patients, with important but limited constraints originating in individual conscience.
\end{abstract}

Keywords: Abortion, Beneficence, Counseling, Feticide, Professional responsibility, Respect for autonomy.

How to cite this article: Chervenak FA, McCullough LB. Professionally responsible for counseling Pregnant Women about Abortion and Feticide. Donald School J Ultrasound Obstet Gynecol 2016;10(3):321-325.

Source of support: Nil

Conflict of interest: None

\section{INTRODUCTION}

One of the most professionally challenging topics in obstetric ethics is the appropriate counseling of pregnant woman about abortion and feticide. This paper provides ethical guidance on when to offer, recommend, perform, and refer for abortion and feticide. This paper is based on the professional responsibility model of obstetric ethics ${ }^{1}$ and its prior application to this topic. ${ }^{2}$

In as much as precise terminology is essential to such an account, we begin by clarifying terminology. "Abortion" and "feticide" are often used without precision. Failure to be clear about their precise meanings can undermine ethical analysis. "Abortion" and "feticide" have precise, descriptive, medical meanings.

\footnotetext{
${ }^{1}$ Professor and Chairman, ${ }^{2}$ Dalton Tomlin Chair

${ }^{1}$ Department of Obstetrics and Gynecology, Weill Medical College of Cornell University, New York, USA

${ }^{2}$ Center for Medical Ethics and Health Policy, Baylor College of Medicine, Houston, Texas, USA

Corresponding Author: Frank A Chervenak, Professor and Chairman, Department of Obstetrics and Gynecology, Weill Medical College of Cornell University, New York, USA, Phone: +2127463184, e-mail: fac2001@med.cornell.edu
}

According to Stedman's Medical Dictionary, abortion is the "[e]xpulsion from the uterus of an embryo or fetus before viability." ${ }^{3}$ Abortion can occur spontaneously or can be induced. Induced abortion, because it occurs before viability, will result in the death of the embryo(s) or fetus(es). Feticide is defined as the "[d]estruction of the embryo or fetus in the uterus" ${ }^{\prime 3}$ independently of gestational age and is not determinative whether the uterus is emptied. Feticide can be performed by such means as injection of potassium chloride or ligation of the umbilical cord. ${ }^{4}$

"Multifetal pregnancy reduction" is the use of feticide to cause the death of embryo(s) or fetus(es), which typically remains in the ongoing pregnancy. ${ }^{4}$ The more precise terminology is "selective feticide," because of the vagueness of the word "reduction," especially for lay audiences. Termination of pregnancy is the "[i]nduced ending of a pregnancy"3 independently of gestational age and is not determinative whether survival occurs. In light of this definition, "selective termination" can be confusing and should not be used, because selective feticide does not end the pregnancy of the surviving fetus(es). In this study, we use "induced abortion" rather than simply "abortion" to be precise that spontaneous abortion is not included. We use "feticide" with the descriptive meaning above. Both "induced abortion" and "feticide" are valueneutral, medical terms.

\section{OFFERING INDUCED ABORTION AND FETICIDE}

Offering induced abortion and feticide may be appropriate after fetal viability when a serious fetal anomaly has been diagnosed. "Serious fetal anomaly" means that there is a certain or near certain diagnosis of an anomaly that is reliably expected either to result in death, even with aggressive obstetric and neonatal intervention, or short-term survival with severe and irreversible deficit of cognitive developmental capacity. We have shown that induced abortion of fetuses of 24 weeks gestational age and later without serious fetal anomalies is not ethically permissible. ${ }^{1}$ After viability, i.e., throughout the third trimester of pregnancy, there is a beneficence-based (Box 1) prohibition against feticide of viable fetuses without serious anomalies, because there is a beneficence-based obligation to protect the life and health of the fetal patient. As a consequence, both the physician and the pregnant woman have 
Box 1: Ethical concept and principles

Autonomy is the capacity to be self-governing in one's decision-making and actions based on such decision-making. Beneficence is an ethical principle that obligates the obstetrician to identify and provide forms of clinical management that in deliberative clinical judgment are expected to result in net clinical benefit for the patient.

Respect for autonomy is an ethical principle that obligates the obstetrician to empower the pregnant woman with information about beneficence-based forms of clinical management and their clinical benefits and risks and also to take reasonable measures to ensure that the pregnant woman's decisionmaking is free from controlling influences.

beneficence-based obligations to protect the health and life of the viable fetal patient without severe anomalies. It follows that it is ethically impermissible to offer feticide for viable fetuses without anomalies or with less-than-severe anomalies, such as Down syndrome or achondroplasia. Less-than-severe anomalies do not involve a high probability of death or a high probability of the absence or virtual absence of cognitive developmental capacity. ${ }^{5,6}$

In contrast, when a viable fetus has a severe anomaly, offering feticide followed by termination of pregnancy is ethically appropriate. This is because the beneficencebased obligation to protect the life of the fetus that has been diagnosed with a severe anomaly has reached its limits: The outcomes of death or of short-term survival with severe and irreversible deficit of cognitive developmental capacity cannot be prevented. . $^{5,6}$

There are two beneficence-based justifications for offering induced abortion before viability. The first is based on a deliberative (evidence-based, rigorous, transparent, and accountable) clinical judgment that continued pregnancy poses a threat to the health or life of the pregnant woman. Preexisting conditions, such as severe cardiac disease or some forms of cancer, can pose such threats. ${ }^{7}$ When the best available evidence supports the clinical judgment that continued pregnancy poses a risk to the pregnant woman's health or life, she should be informed about this matter and offered the alternative of induced abortion.

It is important to appreciate that this beneficencebased justification will evolve over time as new evidence accumulates about the risks of pregnancy to women from preexisting conditions or the complications of pregnancy. Some women, because of moral convictions about the general moral status of the fetus, will refuse this offer. They should be informed that their refusal increases the risk that their health could be severely compromised and that they could die. The final decision to remain pregnant or to elect induced abortion is ultimately a function of the pregnant woman's autonomy (Box 1) and should be respected by the physician.
The second beneficence-based justification for offering feticide before viability is based on deliberative clinical judgment that continued pregnancy poses a threat to offering induced during abortion or feticide the life or health of coexistent fetuses, such as is the case in higherorder pregnancies and twin pregnancies in which the continued existence of the anomalous fetus that is causing hydramnios poses a threat to the health or life of the other fetus. Current evidence supports the clinical judgment that these risks can be reduced by selective feticide. ${ }^{4}$ When the best available evidence supports the clinical judgment that continued multifetal, previable pregnancy poses a risk to the other fetus' or fetuses' health or life, the pregnant woman should be informed about this matter and offered the alternative of selective feticide. Some women, because of moral convictions about the general moral status of the fetus, will refuse this offer. They should be informed that their refusal increases the risk that the pregnancy will end before viability without any surviving fetuses or end prematurely after viability, with increased risk of infant mortality and morbidity. The final decision to remain pregnant, to elect induced abortion, or to elect selective feticide is ultimately a function of the pregnant woman's autonomy and should be respected by the physician.

When the best available evidence supports the deliberative clinical judgment that continued previable pregnancy does not pose an increased risk to the health or life of the pregnant woman or fetuses, the only remaining justification for offering induced abortion or feticide is autonomy-based. There are five clinical circumstances in which induced abortion should be offered. First, some pregnant women will request an induced abortion. Second, a previable pregnancy will be diagnosed with an anomaly or viable pregnancy will be diagnosed with a severe anomaly, e.g., by ultrasound. Third, a complication occurs that threatens the successful continuation of a previable pregnancy, such as preterm premature rupture of membranes. Fourth, a complication may be present in pregnancy that jeopardizes maternal health or life, such as cancer or severe eclampsia. Fifth, some pregnant women will directly, and sometimes indirectly, express concern about remaining pregnant or will be concerned about multiple birth and will prefer for economic or other personal reasons to have a singleton pregnancy. Physicians should respond to women in these five groups by discussing the option of induced abortion and, when appropriate, explaining time limitations.

In response to the offer of induced abortion, physicians should expect pregnant women to sort themselves into three subgroups. ${ }^{8}$ Some will want to continue the pregnancy because they decide to accept whatever child results. Some will not want to remain pregnant and will 
elect induced abortion. Some will be uncertain about whether to continue the pregnancy. Respecting the autonomy (Box 1) of pregnant women means that physicians should respect this self-sorting, by limiting their role to providing information in a nondirective fashion (offering but not recommending induced abortion) that these women can use to resolve their uncertainty. Attempting to bias woman's decision assumes falsely that physicians have the professional competence to decide for a woman with a previable pregnancy that she should or should not remain pregnant.

Nondirective counseling should guide physicians in discussing induced abortion with women with previable pregnancies who remain uncertain. "Nondirective counseling" means that physicians should refrain from making, suggesting, or implying a recommendation about continuation or termination of a previable pregnancy. Directive counseling toward continuation of a previable pregnancy based on alleged benefit to the pregnant woman of providing information about fetal development or showing images of fetal development, to prevent remorse or regret, lacks an evidence base. Such directive counseling is an ethically impermissible distortion of the physician's professional role in the informed consent process. ${ }^{1,9}$ All women should be informed that their decision about termination is time-limited, given the availability of induced abortion. In addition, in order to respect autonomy, the physician should provide frank, evidence-based information about maternal or fetal conditions, even if it is emotionally distressing. Physicians need to make the time available for the sometimes extensive and iterative discussions required to disclose the medical facts and assist the woman to assimilate those medical facts into her decision-making process.

Pregnant women who elect induced abortion or feticide should be assured that ethical and legal obligations of confidentiality will be fulfilled: Others will be informed about the patient's decision only with her explicit permission or, in the case of minors, as required by applicable law. ${ }^{10}$ In particular, should she elect absolute confidentiality, her husband or partner should not be informed. Physicians have no professional competence in this matter, and therefore should respect the pregnant woman's autonomous decisions about whom she wants informed by the physician.

Individual conscience, i.e., the values and beliefs of a physician that arise from sources outside the ethical concept of medicine as a profession, such as upbringing and religion, does not justifiably place limits on the ethics of offering induced abortion or feticide when the above ethical justifications apply. There are two reasons why this is the case. The first is that every physician's obligation to provide appropriate information in the informed consent process is a matter of professional responsibility, not individual conscience. Second, one cannot predict how women will sort themselves in response to offering induced abortion or feticide. Subsequent decisions are a function ultimately of the pregnant woman's autonomy. It is, therefore, a mistake to think that offering induced abortion or feticide makes the physician somehow responsible for the informed, deliberative, and voluntary decisions of a pregnant patient that may not be consistent with the physician's individual conscience, because the physician's offer does not control the pregnant woman's decision-making process; she controls it. ${ }^{11}$

\section{RECOMMENDING INDUCED ABORTION AND FETICIDE}

There are four categories for which recommendations of induced abortion or feticide are justifiably considered. The first is when a maternal condition, or treatment of such a condition, results in increased risk to the pregnant woman's health or life should she continue her pregnancy. The second is when continued pregnancy without induced abortion or feticide substantially increases the risk to the health or life of fetus(es). The third is for feticide when a serious anomaly has been diagnosed.

The fourth occurs in complications that threaten the woman's health or life and salvage of the fetus is clinically hopeless. We will argue that recommendations are not ethically justified for the first three, but only for the fourth.

The first and second categories can be addressed together. The first requires balancing the life and health of the pregnant woman against the health and life of the fetal patient in rare cases, such as some forms of cancer ${ }^{7}$ or mirror syndrome. The second category requires balancing the life and health of multiple fetal patients. These judgments, at first, appear to be purely beneficence-based, and therefore are within the scope of the physician's professional competence to make recommendations, but on closer examination, or not. This is because these judgments involve deciding which health or life is more important. This is ultimately not a beneficence-based judgment but autonomy-based, appealing to the cultural, religious, and other individual beliefs of the pregnant woman. Respecting the pregnant woman's autonomy means that the physician should be nondirective and not seek to bias the woman's decision-making process, e.g., by "soft pedaling" the benefits or overemphasizing the risks of continued pregnancy. No recommendation of induced abortion or feticide is ethically justified when the woman is undecided about how to balance her and the fetal patient's interests. Individual conscience is not implicated because physicians are not responsible for the ultimate balancing judgments that pregnant women 
will make in these tragic circumstances after they been informed about them by their physician. ${ }^{7}$

For the third category, given the nature of severe fetal anomalies, one might think that recommendation of induced abortion or feticide would be justified, e.g., for anencephaly or trisomy. ${ }^{2}$ Women with serious moral convictions about the moral status of the fetus, especially women with religious convictions about the sanctity of fetal life, will experience a recommendation of induced abortion or feticide as profoundly disrespectful of their autonomy. They may experience moral distress when offered this alternative but offering an alternative, while distressful, is not profoundly disrespectful of the conscience and convictions of such pregnant women and is, therefore, ethically permissible.

The fourth category is straightforward in beneficencebased clinical judgment. For complications, such as preterm premature rupture of membranes with chorioamnionitis, the fetal condition is hopeless clinically and the woman's health, and perhaps life, is in danger. There is, therefore, no beneficence-based obligation to the fetus, and there is a strong beneficence-based obligation to the pregnant woman to protect her health or life, which justifies a recommendation for induced abortion.

\section{PERFORMING INDUCED ABORTION AND FETICIDE}

There are two ethical issues concerning performing induced abortion or feticide. The first concerns the method of terminating the pregnancy. The second concerns whether individual conscience places ethically justified barriers on an individual physician's performing induced abortion or feticide.

Before viability, it is ethically permissible in professional medical ethics, and therefore in professional conscience, to perform an induced abortion. This is because, as explained above, the pregnant woman is free to withhold or withdraw the moral status of being a patient from the previable fetus at her discretion. Induced abortion of the previable fetus in such circumstances, therefore, does not involve the killing of a patient and is permissible in professional medical ethics. ${ }^{1,9}$ For the same reason, performing feticide in a previable pregnancy is ethically permissible in professional medical ethics.

Pregnant women should not be presumed to understand that expelling the near-viable fetus or a viable fetus with a severe anomaly from the uterus could result in a live birth and that feticide can prevent this outcome. In such circumstances, live birth creates an increased risk of preventable neonatal morbidity. There is a beneficencebased obligation of the physician and the pregnant woman to prevent this risk. Refusal of feticide can also be seen as contradictory because election of termination of pregnancy means that the pregnant woman does not wish to have a child issue from her current pregnancy. Such contradictory thinking is evidence of significant impairment of autonomous decision making. In such a setting, it is reasonable for the physician to require that the pregnant woman accept feticide as a condition for performing termination of her pregnancy. Performing feticide in this setting also exonerates the physician from being accused of performing a so-called "partial-birth abortion." The correct account is that the physician is evacuating the uterus after ethically justified iatrogenic fetal demise.

Some physicians may have objections in individual conscience to participation in induced abortion or feticide. Respecting individual conscience means that such physicians should be free to refuse to perform induced abortion or feticide. An important implication of this analysis of individual conscience is that a requirement of residents or fellows to participate in induced abortion or feticide is ethically impermissible. However, a requirement that trainees have an appropriate fund of knowledge about these procedures and an appropriate fund of knowledge and clinical skills in managing their complications is consistent with individual conscience and is a matter of professional obligation. ${ }^{1,9}$ Physicians with individual-conscience-based objections to induced abortion or feticide must keep in mind, when they refuse to perform the procedure, that individual conscience does not govern the physician's professional role. It is, therefore, impermissible for the physician, based on the individual conscience, to express judgments about the morality of a woman's election of induced abortion or feticide, or of colleagues who perform these procedures, because doing so is inconsistent with nondirective counseling regarding induced abortion before viability. ${ }^{1,9}$

The obligation of a community to ensure access to termination of pregnancy involves complex and controversial appeals to social justice that are beyond the scope of this paper. While it could be argued that every community has such a social justice-based obligation, social justice itself requires respect for individual conscience and cannot, therefore, mandate violations of individual conscience. An important exception is termination of pregnancy for maternal indications in a medical emergency, such as obstetric hemorrhage or severe intrauterine infection, conditions for which there is no time to transfer the care of the pregnant woman to another physician or facility.

\section{REFERRING FOR INDUCED ABORTION AND FETICIDE}

The ethics of referral for induced abortion and feticide is straightforward for physicians who do not have conscience-based objections to induced abortion. They 
can make what we call direct referrals. ${ }^{12}$ The referring physician sees to it that the patient will be seen by a colleague competent and willing to perform the procedure.

Direct referral appears not to be an option for physicians with a conscience-based objection to induced abortion or feticide, because of the explicit involvement of the physician in the subsequent termination of a pregnancy. To concomitantly respect the pregnant woman's autonomy and the individual conscience of physicians opposed to induced abortion or feticide, an indirect referral for termination of pregnancy should be made. Indirect referral is both autonomy-based and beneficence-based. When it is obligatory to offer induced abortion or feticide, respect for the pregnant woman's autonomy in previable pregnancies requires the physician to inform her that induced abortion or feticide is an option. Beneficence requires the physician to provide information about clinics or agencies, such as Planned Parenthood in the United States, that provide competent and safe induced abortion or feticide. The physician's individual conscience is not violated, because whether an induced abortion or feticide subsequently occurs is solely a function of the pregnant woman's autonomy after she visits the clinic or agency of her own accord. The referring physician is, therefore, not responsible for a subsequent induced abortion or feticide. In summary, direct referral for induced abortion or induced abortion and infanticide feticide is not ethically required but is ethically permissible. Consciencebased objections to direct referral for induced abortion or feticide have merit; conscience-based objections to indirect referral do not. ${ }^{12}$

\section{CONCLUSION}

The professional responsibility model of perinatal ethics provides guidance for decision making about offering, recommending, performing, and referring for induced abortion or feticide. The result is a comprehensive account that respects autonomy-based and beneficencebased obligations to the pregnant woman, beneficencebased obligations to the fetal patient, the professional responsibility of physicians, and the individual conscience of physicians opposed to induced abortion or feticide. The physician's role in offering, recommending, performing, and referring for induced abortion or feticide is based primarily on professional responsibility, shaped by autonomy-based and beneficence-based obligations of the physician, with important but limited constraints originating in individual conscience.

\section{REFERENCES}

1. Chervenak FA, McCullough LB, Brent RL. The professional responsibility model of obstetric ethics: avoiding the perils of clashing rights. Am J Obstet Gynecol 2011 Oct;205(4):315.e1-315.e5.

2. Chervenak FA, McCullough LB. An ethically justified practical approach to offering, recommending, performing, and referring for induced abortion and feticide. Am J Obstet Gynecol 2009 Dec;201(6):560.e1-560.e6.

3. Stedman's Medical Dictionary. Accessed 2015 Sep 26. Available from: http://online.statref.com/DictionaryHelp/DictionaryHelp.\%20aspx?type $=$ dictionary\&SessionId $=\mathrm{E} 64234$ MHHTKYZGGZ\&prnt=dlo\&chwin=false.

4. Committee on Ethics. ACOG committee opinion. Number 369. June 2007. Multifetal pregnancy reduction. Obstet Gynecol 2007 Jun;109(6):1511-1515.

5. Chervenak FA, McCullough LB, Campbell S. Is third trimester abortion justified? Br J Obstet Gynaecol 1995 Jun;102(6): 434-435.

6. Chervenak FA, McCullough LB, Campbell S. Third trimester abortion: is compassion enough? Br J Obstet Gynaecol 1999 Apr;106(4):293-296.

7. Chervenak FA, McCullough LB, Knapp RC, Caputo TA, Barber HR. A clinically comprehensive ethical framework for offering and recommending cancer treatment before and during pregnancy. Cancer 2004 Jan 15;100(2):215-222.

8. Chervenak FA, McCullough LB, Sharma G, Davis J, Gross S. Enhancing patient autonomy with risk assessment and invasive diagnosis: an ethical solution to a clinical challenge. Am J Obstet Gynecol 2008 Jul;199(1):19.e1-19.e4.

9. Chervenak FA, McCullough LB. The professional responsibility model of perinatal ethics. Berlin: Walter de Gruyter; 2014.

10. American Medical Association. Code of Medical Ethics. Chapter 3. Opinion 3.2.1. Confidentiality. Accessed 2016 Aug 12. Available from: http://www.ama-assn.org/ama/pub/ physician-resources/medical-ethics/code-medical-ethics. page?

11. Thorp JM, Wells SR, Bowes WA Jr, Cefalo RC. Integrity, abortion, and the pro-life perinatologist. Hastings Cent Rep 1995 Jan-Feb;25(1):27-28.

12. Chervenak FA, McCullough LB. The ethics of direct and indirect referral for termination of pregnancy. Am J Obstet Gynecol 2008 Sep;199(3):232.e1-232.e3. 